Edited by Kiriakos Xenitidis and
Colin Campbell
Contents
- Early intervention in anorexia nervosa
- Accuracy of death certification

\section{Early intervention in anorexia nervosa}

It is indeed rewarding to see that Treasure \& Russell, in their editorial on early intervention in anorexia nervosa, ${ }^{1}$ offer much in support of it. Over many years our therapeutic approach in Bristol placed great emphasis on getting patients into treatment as soon as possible after the onset of anorexia. This was supported by evidence from a study which compared outcome in Bristol with two other treatment centres. ${ }^{2}$ In line with this we emphasised the importance of developing local, easily accessible treatment facilities.

Given their welcome support for close involvement of relatives in the treatment process, Treasure \& Russell might well have also included family processes along with the several brain mechanisms that they evaluate as possible reasons why early intervention may be important. If the illness continues for any length of time, such factors as loss of heart by relatives and increased blame for failure to respond to help can lead to the progressive alienation of the relative with anorexia and impairment of the family's ability to contribute constructively to treatment. Although negative attitudes have long been recognised, they remain a serious obstacle to the development of effective treatments of anorexia nervosa. Surely further research is still required into understanding them more fully as well as into their prevention and management, especially when the illness is at risk of becoming chronic.

1 Treasure J, Russell G. The case for early intervention in anorexia nervosa: theoretical exploration of maintaining factors. Br J Psychiatry 2011; 199: 5-7.

2 Morgan HG, Purgold J, Welbourne J. Management and outcome in anorexia nervosa: a standardised prognostic study. Br J Psychiatry 1983; 143 282-7.

Gethin Morgan, Emeritus Professor of Mental Health, University of Bristol, UK. Email: hilary.howard@blueyonder.co.uk

doi: 10.1192/bjp.199.5.432

Authors' reply: We thank Professor Morgan for responding to our editorial and raising two important points. First, he is correct in saying that there was already some evidence favouring the outcome in anorexia nervosa if patients were enrolled in treatment as soon as possible after the onset of the illness. This came from his follow-up study of patients treated in Bristol where the emphasis was on local, easily accessible treatments. The outcome in the Bristol patients was significantly better than in those treated in two London hospitals providing 'national services' (Maudsley and St George's Hospitals). This difference favouring Bristol was acknowledged by other experts in the field. ${ }^{1}$ But in his 1982 article, Professor Morgan had already acknowledged the difficulty of assessing different therapeutic approaches in view of the selection of patients. It is inescapable that an evaluation of the treatment requires randomised controlled trials, as in the studies of family therapy reviewed in our editorial.

Professor Morgan's second point was to stress that family processes are crucial in contributing to the success of early intervention in anorexia nervosa. He is right in recognising the risks of alienation in the patients' relatives which undermines their contributions to a successful treatment. Again we welcome his observations enabling us to expand our too brief description of the essential principles of successful family therapy: (a) exonerating parents from causing the illness; and (b) getting them to take joint control of their child's eating so that they are enabled to maintain a normal body weight.

These principles need some elaboration. Exonerating the parents requires the therapist to communicate a neutral position regarding the causes of the illness. The medical pioneers in this field of study (e.g. Gull, Charcot) expressed strongly negative views about relatives' poor management of the problem, views which should be dispelled. Charcot's influence was, of course, strongest in France where the cure d'isolement has only been abandoned within recent memory.

The second essential requirement is fraught with difficulties. Parents at first resist taking the necessary action. Their experience leads them to believe that they have failed to prevent their child's poor eating and weight loss. Some parents fear that firmness on their part will lead to a loss of their child's affection. They may also jump to the conclusion that an invitation to participate in treatment implies that they are being blamed. This can be combated by expressing the aims of therapy not as 'changing the family' but rather as helping them treat a sick family member. ${ }^{2}$

Successful management requires an ongoing search for emotional and interpersonal factors (e.g. expressed emotion), which are responsible for maintaining (rather than causing) harmful behaviours. J.T. has contributed to a practical manual describing the techniques for negotiating successful transactions between carer and adolescent, focusing on rapport, language and problem-solving skills. ${ }^{3,4}$

1 Theander S. Outcome and prognosis in anorexia nervosa and bulimia. Some results of previous investigations, compared with a Swedish long-term study. J Psychosom Res 1985; 19: 493-508.

2 Russell G. Anorexia nervosa. In New Oxford Textbook of Psychiatry. Second Edition (eds MG Gelder, NC Andreasen, JJ Lopez-lbor, et al): 788 \& 790-2. Oxford University Press.

3 Treasure J, Smith G, Crane A. Skills-based Learning for Caring for a Loved One with an Eating Disorder: The New Maudsley Method. Routledge, 2007.

4 Goddard E, Macdonald P, Sepulveda AR, Nauman U, Landau S, Schmidt U, et al. Cognitive interpersonal maintenance model of eating disorders: intervention for carers. Br J Psychiatry 2011; 199: 225-31.

Janet Treasure, Institute of Psychiatry, King's College London, UK. Email: janet.treasure@kcl.ac.uk; Gerald Russell, Institute of Psychiatry, King's college London, UK

doi: 10.1192/bjp.199.5.432a

\section{Accuracy of death certification}

The death certificate allows underlying conditions leading to the cause of death, as well as other significant conditions unrelated to the immediate cause of death, to be listed. Perusal of statistics of the causes of death is instructive. The list of drugs in the Office for National Statistics' Statistical Bulletin on deaths related to drug poisoning in England and Wales includes illicit and prescription drugs. Tricyclic antidepressants, dosulepin, selective serotonin reuptake inhibitors, benzodiazepines and hypnotics are detailed as well as individual illegal substances. ${ }^{1}$ 